\title{
THE MULTIPOINT INITIAL-FINAL VALUE CONDITION FOR THE NAVIER - STOKES LINEAR MODEL
}

S.A. Zagrebina, South Ural State University, Chelyabinsk, Russian Federation, zagrebina_sophiya@mail.ru,

A.S Konkina, South Ural State University, Chelyabinsk, Russian Federation, alexandra.konkina@yandex.ru

The Navier - Stokes system models the dynamics of a viscous incompressible fluid. The problem of existence of solutions of the Cauchy - Dirichlet problem for this system is included in the list of the most serious problems of this century. In this paper it is proposed to consider the multipoint initial-final conditions instead of the Cauchy conditions. It should be noted that nowadays the study of solvabilityof initial-final value problems is a new and actively developing direction of the Sobolev type equations theory. The main result of the paper is the proof of unique solvability of the stated problem for the system of Navier Stokes equations.

Keywords: relatively $p$-sectorial operators; the multipoint initial-final value condition; the Navier - Stokes linear model.

Assume that $\Omega \subset \mathbb{R}^{n}, n=\mathbb{N} \backslash\{1\}$, is a bounded domain with boundary $\partial \Omega$ of class $C^{\infty}$. In the cylinder $\Omega \times \mathbb{R}_{+}$consider the Dirichlet problem

$$
v(x, t)=0, \quad(x, t) \in \partial \Omega \times \mathbb{R}_{+}
$$

for the system of equations

$$
v_{t}=\nu \nabla^{2} v-\nabla p, \quad \nabla \cdot v=0,
$$

which models a linear approximation of dynamics of a viscous incompressible fluid. Transfer system (2) to

$$
v_{t}=\nu \nabla^{2} v-p, \quad \nabla(\nabla \cdot v)=0,
$$

replacing $\nabla p \rightarrow p$ [1]. This approach is different from the proposed in classical monographs [2,3]. It is based on [4] and was developed in [1, 5,6]. This article focuses on study of solvability of multipoint initial-final problem for the classical linear Navier - Stokes model (1), (3).

1. Multipoint Initial-Final Conditions. Assume that $\mathfrak{U}$ and $\mathfrak{F}$ are Banach spaces, consider a continuous linear operator. $L \in \mathcal{L}(\mathfrak{U} ; \mathfrak{F})$ and a closed linear operator $M \in \mathcal{C l}(\mathfrak{U} ; \mathfrak{F})$ whose domain is dense in $\mathfrak{U}$ Let $M$ be $(L, p)$-sectorial, $p \in\{0\} \cup \mathbb{N}$. Consider problem (1), (3). It can be reduced to a linear Sobolev type equation

$$
L \dot{u}=M u+f .
$$

Recall that the condition of $(L, p)$-sectoriality of operator $M$ is a sufficient condition for the existence of degenerate analytic semigroups of operators

$$
U^{t}=\frac{1}{2 \pi i} \int_{\Gamma}(\mu L-M)^{-1} L e^{\mu t} d \mu \quad \text { and } \quad F^{t}=\frac{1}{2 \pi i} \int_{\Gamma} L(\mu L-M)^{-1} e^{\mu t} d \mu
$$

defined on spaces $\mathfrak{U}$ and $\mathfrak{F}$ accordingly (terminology and results see in 3 [7]). Introduce the kernel ker $U^{\cdot}=\mathfrak{U}^{0}, \operatorname{ker} F^{\cdot}=\mathfrak{F}^{0}$ and image $\operatorname{im} U^{\cdot}=\mathfrak{U}^{1}, \operatorname{im} F^{\cdot}=\mathfrak{F}^{1}$ of these semigroups. It is easy to show that $\overline{\mathfrak{U}^{0} \oplus \mathfrak{U}^{1}}=\overline{\mathfrak{U}^{0}} \oplus \overline{\mathfrak{U}^{1}}=\mathfrak{U}^{0} \oplus \mathfrak{U}^{1}, \overline{\mathfrak{F}^{0} \oplus \mathfrak{F}^{1}}=\overline{\mathfrak{F}^{0}} \oplus \overline{\mathfrak{F}^{1}}=\mathfrak{F}^{0} \oplus \mathfrak{F}^{1}$. We need a stronger statement

$$
\mathfrak{U}^{0} \oplus \mathfrak{U}^{1}=\mathfrak{U} \quad\left(\mathfrak{F}^{0} \oplus \mathfrak{F}^{1}=\mathfrak{F}\right),
$$

which occurs in the case of either strongly $(L, p)$-sectorial operator $M$ of the right (left), $p \in$ $\{0\} \cup \mathbb{N}$, or reflexivity of $\mathfrak{U}(\mathfrak{F})$ (see [1] and references therein). 
Denote by $L_{k}\left(M_{k}\right)$ the restriction of $L(M)$ on $\mathfrak{U}^{k}\left(\operatorname{dom} M \cap \mathfrak{U}^{k}\right), k=0,1$. If operator $M$ is strongly $(L, p)$-sectorial on the right (left), $p \in\{0\} \cup \mathbb{N}$, then $L_{k} \in \mathcal{L}\left(\mathfrak{U}^{k} ; \mathfrak{F}^{k}\right), M_{k} \in \mathcal{C l}\left(\mathfrak{U}^{k} ; \mathfrak{F}^{k}\right)$, $k=0,1$, and there exists an operator $M_{0}^{-1} \in \mathcal{L}\left(\mathfrak{F}^{0} ; \mathfrak{U}^{0}\right)$, and projector $P=s-\lim _{t \rightarrow 0+} U^{t},(Q=$ $\left.s-\lim _{t \rightarrow 0+} F^{t}\right)$ splitting space $\mathfrak{U}(\mathfrak{F})$ according to $(\mathrm{A} 1)$, so that $\mathfrak{U}^{1}=\operatorname{im} P\left(\mathfrak{F}^{1}=\operatorname{im} Q\right)$.

Introduce another condition:

$$
\text { there exists an operator } L_{1}^{-1} \in \mathcal{L}\left(\mathfrak{F}^{1} ; \mathfrak{U}^{1}\right),
$$

which occurs in the case of strongly $(L, p)$-sectorial operator $M, p \in\{0\} \cup \mathbb{N}$. Previously, it was shown that (A1) together with the condition of $(L, p)$-sectoriality of operator $M, p \in\{0\} \cup \mathbb{N}$, gives strong $(L, p)$-sectoriality of operator $M$ on the right (left), $p \in\{0\} \cup \mathbb{N}$, and if we add it to condition (A2), we get the strongly $(L, p)$-sectorial operator $M, p \in\{0\} \cup \mathbb{N}$ (see [1] and references therein). Then the operator $G=M_{0}^{-1} L_{0} \in \mathcal{L}\left(\mathfrak{U}^{0}\right)$ is nilpotent of degree $p$, and the operator $S=L_{1}^{-1} M_{1} \in \mathcal{C l}\left(\mathfrak{U}^{1}\right)$ is sectorial.

Finally, introduce another important condition for the relative spectrum of operator $M$ [8]:

$$
\left.\begin{array}{c}
\sigma^{L}(M)=\bigcup_{j=0}^{n} \sigma_{j}^{L}(M), n \in \mathbb{N} \text {, where } \sigma_{j}^{L}(M) \neq \emptyset \text { is contained in a bounded } \\
\text { domain } D_{j} \subset \mathbb{C} \text { with piecewise smooth boundary } \partial D_{j}=\Gamma_{j} \subset \mathbb{C} \text {. Moreover, } \\
\overline{D_{j}} \cap \sigma_{0}^{L}(M)=\emptyset \text { and } \overline{D_{k}} \cap \overline{D_{l}}=\emptyset \text { for all } j, k, l=\overline{1, n}, k \neq l .
\end{array}\right\}
$$

Construct a relatively spectral projectors [8] $P_{j} \in \mathcal{L}(\mathfrak{U})$ and $Q_{j} \in \mathcal{L}(\mathfrak{F}), j=\overline{1, n}$, given by

$$
P_{j}=\frac{1}{2 \pi i} \int_{\Gamma_{j}}(\mu L-M)^{-1} L d \mu, Q_{j}=\frac{1}{2 \pi i} \int_{\Gamma_{j}} L(\mu L-M)^{-1} d \mu, j=\overline{1, n} .
$$

and it turns out that under the condition of $(L, p)$-sectoriality of operator $M$ and conditions (A1), (A2), $P_{j} P=P P_{j}=P_{j}$ and $Q_{j} Q=Q Q_{j}=Q_{j}, j=\overline{1, n}$. Therefore, in this case there is a projector $P_{0}=P-\sum_{j=1}^{n} P_{j}, P_{0} \in \mathcal{L}(\mathfrak{U})$.

So, suppose that conditions (A1) - (A3) hold, commit $\tau_{j} \in \mathbb{R}_{+}\left(\tau_{j}<\tau_{j+1}\right), u_{j} \in \mathfrak{U}, j=\overline{0, n}$, and consider the multipoint initial-final value condition

$$
P_{j}\left(u\left(\tau_{j}\right)-u_{j}\right)=0, \quad j=\overline{0, n}
$$

for linear Sobolev type equation (4). Vector function $u \in C^{1}\left(\left(\tau_{0}, \tau_{n}\right) ; \mathfrak{U}\right) \cap C\left(\left[\tau_{0}, \tau_{n}\right] ; \mathfrak{U}\right)$, satisfying equation (4), is called a solution; the solution $u=u(t)$ of $(4)$ is called a solution of multipoint initial-final value problem (4), (6), if in addition $\lim _{t \rightarrow \tau_{0}+} P_{0}\left(u(t)-u_{0}\right)=0$ and $P_{j}\left(u\left(\tau_{j}\right)-u_{j}\right)=0$, $j=\overline{1, n}$.

The study of solvability of the initial-final value problems for nonclassical equations of mathematical physics, including higher order, is actively developing as well as the problem of optimal control of these solutions (see for example, [1] and references therein).

2.Unique Solvability of Abstract Problem. Assume that $\mathfrak{U}$ and $\mathfrak{F}$ are Banach spaces, take $L \in \mathcal{L}(\mathfrak{U} ; \mathfrak{F})$ and $M \in \mathcal{C l}(\mathfrak{U} ; \mathfrak{F})$ such that $M$ is an $(L, p)$-sectorial operator and assume that (A1) - (A3) hold.

Theorem 1. If $M$ is an $(L, p)$-sectorial operator, and (A1)-(A3) hold. Then

$$
U^{t}=\sum_{j=1}^{n} P_{j} U^{t}+P_{0} U^{t}=\sum_{j=1}^{n} U_{j}^{t}+U_{0}^{t}, \quad F^{t}=\sum_{j=1}^{n} Q_{j} F^{t}+Q_{0} F^{t}=\sum_{j=1}^{n} F_{j}^{t}+F_{0}^{t},
$$


mereover, we can express $U_{j}^{t}$ and $F_{j}^{t}$ in the form

$$
U_{j}^{t}=\frac{1}{2 \pi i} \int_{\Gamma_{j}}(\mu L-M)^{-1} L e^{\mu t} d \mu, \quad F_{j}^{t}=\frac{1}{2 \pi i} \int_{\Gamma_{j}} L(\mu L-M)^{-1} e^{\mu t} d \mu, j=\overline{1, n} .
$$

Denote by $\mathfrak{U}^{1 j}=\operatorname{im} P_{j}$ and $\mathfrak{F}^{1 j}=\operatorname{im} Q_{j}, j=\overline{0, n}$. By construction

$$
\mathfrak{U}^{1}=\bigoplus_{j=0}^{n} \mathfrak{U}^{1 j} \text { and } \mathfrak{F}^{1}=\bigoplus_{j=0}^{n} \mathfrak{F}^{1 j}
$$

Denote by $L_{j} \quad\left(M_{j}\right)$ the restriction of $L \quad(M)$ on $\mathfrak{U}^{1 j} \quad\left(\operatorname{dom} M \cap \mathfrak{U}^{1 j}\right)$, $j=\overline{0, n}$. It is easy to show that the operators $L_{j} \in \mathcal{L}\left(\mathfrak{U}^{1 j} ; \mathfrak{F}^{1 j}\right), \quad M_{j} \in \mathcal{C l}\left(\mathfrak{U}^{1 j} ; \mathfrak{F}^{1 j}\right)$, $j=\overline{0, n}$, and by virtue of (A2) there exists an operator $L_{j}^{-1} \in \mathcal{L}\left(\mathfrak{F}^{1 j} ; \mathfrak{U}^{1 j}\right), j=\overline{0, n}$. Also, it is easy to show that the operator $S_{0}=L_{0}^{-1} M_{0} \in \mathcal{C l}\left(\mathfrak{U}_{0}\right)$ is sectorial, and the operator $S_{j}=L_{j}^{-1} M_{j}: \mathfrak{U}^{1 j} \rightarrow \mathfrak{U}^{1 j}, j=\overline{1, n}$ is bounded. Now we are ready to prove the unique solvability of problem (6) for equation (4) that is due to $(L, p)$-sectoriality of operator $M$, conditions (A1) - (A3) is reduced to the form

$$
\begin{gathered}
G \dot{u}^{0}=u^{0}+M_{0}^{-1} f^{0}, \\
\dot{u}^{1 j}=S_{j} u^{1 j}+L_{1 j}^{-1} f^{1 j}, j=\overline{0, n}
\end{gathered}
$$

where $f^{0}=(\mathbb{I}-Q) f, f^{1 j}=Q_{j} f, u^{0}=(\mathbb{I}-P) u, u^{1 j}=P_{j} u, j=\overline{0, n}$.

Theorem 2. [8] If $M$ is an (L,p)-sectorial operator and (A1) - (A3) hold. Then for any vector function $f^{0} \in C^{p}\left(\left[\tau_{0}, \tau_{n}\right] ; \mathfrak{F}^{0}\right) \cap C^{p+1}\left(\left(\tau_{0}, \tau_{n}\right) ; \mathfrak{F}^{0}\right), f^{1} \in C\left(\left[\tau_{0}, \tau_{n}\right] ; \mathfrak{F}^{1}\right)$ there exists a unique solution of problem (4), (6), which also has the form

$$
u(t)=-\sum_{q=1}^{p} G^{q} M_{0}^{-1} f^{0(q)}(t)+\sum_{j=1}^{n}\left(U_{j}^{t-\tau_{j}} u_{j}+\int_{\tau_{j}}^{t} U_{j}^{t-s} L_{1 j}^{-1} Q_{j} f(s) d s\right) .
$$

3. Specific Interpretation. Assume that $\Omega \subset \mathbb{R}^{n}, n=\mathbb{N} \backslash\{1\}$, is a bounded domain with boundary $\partial \Omega$ of class $C^{\infty}$. For the reduction of problem (1), (3) to the homogeneous equation (4) $(f \equiv 0)$ we need the functional spaces from [4]. Assume that $\mathbb{H}_{\sigma}^{2}$ and $\mathbb{H}_{\pi}^{2}\left(\mathbb{H}_{\sigma}\right.$ and $\left.\mathbb{H}_{\pi}\right)$ are subspaces of solenoidal and potential vector functions of space $\mathbb{H}^{2}=\left(W_{2}^{2}(\Omega) \cap \stackrel{\circ}{W}(\Omega)\right)^{n}\left(\mathbb{L}^{2}=\left(L^{2}(\Omega)\right)^{n}\right)$. Formula $A=\operatorname{diag}\left\{\nabla^{2}, \ldots, \nabla^{2}\right\}$ defines a linear continuous operator with discrete finite-negative spectrum $\sigma(A)$, thicken only to $-\infty$. Denoted by $A_{\sigma(\pi)}$ the restriction of $A$ on $\mathbb{H}_{\sigma(\pi)}^{2}$.

Lemma 1. (Solonnikov - Vorovich - Yudovich theorem). Operator $A_{\sigma(\pi)} \in \mathcal{L}\left(\mathbb{H}_{\sigma(\pi)}^{2}, \mathbb{H}_{\sigma(\pi)}\right)$, moreover $\sigma\left(A_{\sigma(\pi)}\right)=\sigma(A)$ and $A=A_{\sigma} \Sigma+A_{\pi} \Pi$.

Herein $\Pi \in \mathcal{L}\left(\mathbb{H}^{2}, \mathbb{H}_{\pi}^{2}\right)$ designates a projector along $\mathbb{H}_{\sigma}^{2}, \Sigma=\mathbb{I}-\Pi$.

Lemma 2. (Kapitanski - Pileckas theorem). Formula $B: u \rightarrow \nabla(\nabla \cdot u)$ defines the operator $B \in \mathcal{L}\left(\mathbb{H}^{2}, \mathbb{H}_{\pi}\right)$, with $\operatorname{ker} B=\mathbb{H}_{\sigma}^{2}$.

Let $\mathfrak{U}=\mathfrak{F} \equiv \mathbb{H}_{\sigma} \times \mathbb{H}_{\pi} \times \mathbb{H}_{p}$, where $\mathbb{H}_{p}=\mathbb{H}_{\pi}$, vector $u \in \mathfrak{U}$ have the form $u=\left(u_{\sigma}, u_{\pi}, u_{p}\right)$. By formulas

$$
L=\left(\begin{array}{lll}
\mathbb{I} & \mathbb{O} & \mathbb{O} \\
\mathbb{O} & \mathbb{I} & \mathbb{O} \\
\mathbb{O} & \mathbb{O} & \mathbb{O}
\end{array}\right), \quad M=\left(\begin{array}{ccc}
\nu A_{\sigma} & \mathbb{O} & \mathbb{O} \\
\mathbb{O} & \nu A_{\pi} & -\mathbb{I} \\
\mathbb{O} & B & \mathbb{O}
\end{array}\right)
$$

define the operator $L \in \mathcal{L}(\mathfrak{U} ; \mathfrak{F}), \operatorname{im} L=\mathbb{H}_{\sigma} \times \mathbb{H}_{\pi} \times\{0\}$, ker $L=\{0\} \times\{0\} \times \mathbb{H}_{p}$ and $M \in \mathcal{C l}(\mathfrak{U} ; \mathfrak{F})$, $\operatorname{dom} M=\mathbb{H}_{\sigma}^{2} \times \mathbb{H}_{\pi}^{2} \times \mathbb{H}_{p}$. Thus, the reduction of model (1), (3) to (4) is finished. 
Lemma 3. [5] For all $\nu \in \mathbb{R}_{+}$operator $M$ is strongly $(L, 1)$-sectorial.

Construct a subspace $\mathfrak{U}^{0}=\mathfrak{F}^{0}=\{0\} \times \mathbb{H}_{\pi} \times \mathbb{H}_{p}, \mathfrak{U}^{1}=\mathfrak{F}^{1}=\mathbb{H}_{\sigma} \times\{0\} \times\{0\}$. Obviously conditions (A1) and (A2) are fulfilled, and

$$
M_{0}^{-1}=\left(\begin{array}{cc}
\mathbb{O} & B_{\pi}^{-1} \\
-\mathbb{I} & \nu A_{\pi} B_{\pi}^{-1}
\end{array}\right),
$$

where $B_{\pi}$ is a restriction of $B$ on $\mathbb{H}_{\pi}^{2}$ (Lemma 2 implies that $B_{\pi}: \mathbb{H}_{\pi}^{2} \rightarrow \mathbb{H}_{\pi}$ is a toplinear isomorphism). It is also easy to verify that

$$
M_{0}^{-1} L_{0}=\left(\begin{array}{cc}
\mathbb{O} & -\mathbb{I} \\
\mathbb{O} & \mathbb{O}
\end{array}\right)
$$

is a nilpotent operator of degree 1 .

Denote by $\sigma(A)=\left\{\lambda_{k}\right\}$, the spectrum of $A$, where $\lambda_{k} \in \mathbb{R}_{-}$are eigenvalues, numbered in nonincreasing order considering their multiplicity, then $\sigma^{L}(M)=\left\{\nu^{-1} \lambda_{k}\right\}$. It is clear that for such set, we can choose the contours $\Gamma_{j} \in \mathbb{C}$, which would satisfy the condition (A3).

Construct

$$
U_{j}^{t}=\left(\begin{array}{ccc}
\sum_{\nu^{-1} \lambda_{k} \in \sigma_{j}^{L}(M)} e^{\nu \lambda_{k} t}\left\langle\cdot, \varphi_{k}\right\rangle \varphi_{k} & \mathbb{O} & \mathbb{O} \\
\mathbb{O} & \mathbb{O} & \mathbb{0} \\
\mathbb{O} & \mathbb{O} & \mathbb{O}
\end{array}\right) j=\overline{0, n} .
$$

Then, by Theorem 2 and Lemma 3 we have the following

Theorem 3. For all $\nu \in \mathbb{R}_{+}, \tau_{j} \in \mathbb{R}_{+}\left(\tau_{j}<\tau_{j+1}\right), u_{j} \in \mathfrak{U}, j=\overline{0, n}$, there exists a unique solution of problem (6) for model (1), (3), and this solution $u=u(t)$ has the form $u_{\sigma}(t)=\sum_{j=0}^{n} U_{j}^{t-\tau_{j}} u_{\tau_{j} \sigma}$, $u_{\pi} \equiv 0, u_{p} \equiv 0$

In conclusion, the authors consider it their pleasant duty to express their sincere gratitude to G.A. Sviridyuk for fruitful discussions.

\section{References}

1. Zagrebina S.A. The Initial-Finite Problems for Nonclassical Models of Mathematical Physics. Bulletin of the South Ural State University. Series: Mathematical Modelling, Programming E6 Computer Software, 2013, vol. 6, no. 2, pp. 5-24.

2. Ladyzhenskaya O.A. The Mathematical Theory of Viscous Incompressible Flow. N.-Y., London, Paris, Gordon and Breach, Science Publ., 1969.

3. Temam, R. Navier-Stokes Equations. Theory and Numerical Analysis. Amsterdam, N.-Y., Oxford, North Holland Publ. Co., 1979.

4. Sviridyuk G.A. On a Model of the Dynamics of a Weakly Compressible Viscoelastic Fluid. Russian Mathematics (Izvestiya VUZ. Matematika), 1994, vol. 38, no. 1, pp. 59-68.

5. Sviridyuk G.A., Kuznetsov G.A., Relatively Strongly p- Sectorial Linear Operators. Doklady Mathematics, 1999, vol. 59, no. 2, pp. 298-300.

6. Matveeva O.P., Sukacheva T.G. Matematicheskie modeli vyazkouprugikh neszhimaemykh zhidkostey nenulevogo poryadka [The Mathematical Model of a Viscoelastic Incompressible Fluid of Nonzero Order]. Chelyabinsk, Publishing Center of South Ural State University, 2014. (in Russian)

7. Sviridyuk G.A., Fedorov V.E. Linear Sobolev Type Equations and Degenerate Semigroups of Operators. Utrecht, Boston, Köln, Tokyo, VSP, 2003. DOI:10.1515/9783110915501 
8. Zagrebina S.A. Multipoint Initial-Final Value Problem for the Linear Model of Plane-Parallel Thermal Convection in Viscoelastic Incompressible Fluid. Bulletin of the South Ural State University. Series: Mathematical Modelling, Programming 83 Computer Software, 2014, vol. 7 , no. 3 , pp. $5-22$.

Received September 24, 2014

УДК 517.9

DOI: $10.14529 / \mathrm{mmp} 150111$

\title{
МНОГОТОЧЕЧНОЕ НАЧАЛЬНО-КОНЕЧНОЕ УСЛОВИЕ ДЛЯ ЛИНЕЙНОЙ МОДЕЛИ НАВЬЕ - СТОКСА
}

\author{
С.А. Загребина, А.С. Конкина
}

Система уравнений Навье - Стокса моделирует динамику вязкой несжимаемой жидкости. Проблема существования решений задачи Коши - Дирихле для этой системы вошла в список наиболее тяжелых математических проблем нынешнего века. В данной статье вместо условия Коши предложено рассматривать многоточечные начальноконечные условия. Необходимо отметить, что в настоящее время в теории уравнений соболевского типа, к которым можно отнести систему Навье - Стокса, активно развивается новое направление исследований - разрешимость начально-конечных задач. Основным результатом статьи является доказательство однозначной разрешимости поставленной задачи.

Ключевые слова: относительно р-секториальные операторы; многоточечное начально-конечное условие; линейная модель Навъе - Стокса.

\section{Литература}

1. Загребина, С.А. Начально-конечные задачи для неклассических моделей математической физики // Вестник ЮУрГУ. Серия: Математическое моделирование и программирование. - 2013. - Т. 6, № 2. - С. 5-24.

2. Ladyzhenskaya, O.A. The Mathematical Theory of Viscous Incompressible Flow. - N.-Y., London, Paris, Gordon and Breach, Science Publ., 1969.

3. Temam, R. Navier - Stokes Equations. Theory and Numerical Analysis. - Amsterdam, N.-Y., Oxford, North Holland Publ. Co., 1979.

4. Свиридюк, Г.А. Об одной модели динамики слабосжимаемой вязкоупругой жидкости / Г.А. Свиридюк // Известия вузов. Математика. - 1994. - № 1. - С. 62-70.

5. Свиридюк, Г.А. Об относительно сильной $p$-секториальности линейных операторов / Г.А. Свиридюк, Г.А. Кузнецов // Доклады Академии наук. - 1999. - Т. 365, № 6. C. $736-738$.

6. Матвеева, О.П. Математические модели вязкоупругих несжимаемых жидкостей ненулевого порядка: монография / О.П. Матвеева, Т.Г. Сукачева. - Челябинск, Издат. центр ЮУрГУ, 2014.

7. Sviridyuk, G.A. Linear Sobolev Type Equations and Degenerate Semigroups of Operators / G.A. Sviridyuk, V.E. Fedorov. - Utrecht; Boston; Köln; Tokyo: VSP, 2003.

8. Zagrebina, S.A. Multipoint Initial-Final Value Problem for the Linear Model of Plane-Parallel Thermal Convection in Viscoelastic Incompressible Fluid // Вестник ЮУрГУ. Серия: Математическое моделирование и программирование. - 2014. - Т. 7, № 3. - С. 5-22.

Софья Александровна Загребина, доктор физико-математических наук, кафедра «Дифференциальные и стохастические уравнения», Южно-Уральский государственный университет (г. Челябинск, Российская Федерация), zagrebina_sophiya@mail.ru.

Александра Сергеевна Конкина, магистрант, кафедра «Уравнения математической физики», Южно-Уральский государственный университет (г. Челябинск, Российская Федерация), alexandra.konkina@yandex.ru.

Поступила в редакцию 24 сентлбрл 2014 г. 